Artículo recibido el 9 de agostode 2020. Aceptado para publicación el 18 de noviembre de 2020

\title{
Classificação dos modos como a (etno)matemática se expressa nos provérbios populares portugueses
}

\section{Classification of the modes in which (ethno)mathematics is expressed in Portuguese popular proverbs}

\begin{abstract}
Resumo
Os provérbios populares portugueses são de grande riqueza e encerram conhecimento e saber-fazer em múltiplas áreas da vivência popular que importa descobrir e preservar. Não temos conhecimento de estudos sobre a etnomatemática existente nos provérbios populares portugueses. Dada a riqueza destes e a potencialidade de utilização no ensino e na aprendizagem da matemática, propomo-nos apresentar aqui uma abordagem iniciadora ao assunto. De um núcleo de cerca de 2000 provérbios, num primeiro nível de análise procedemos à identificação dos conceitos matemáticos existentes. Num segundo nível de análise, procedemos à categorização do modo como a (etno)matemática surge nos provérbios populares portugueses. Estabelecemos três categorias: Modo 1 Explícito, Modo 2 Implícito e Modo 3 Subtil. Ilustramos cada categoria e explicamos a etnomatemática envolvida de modo a deixar claro a possível utilização dos provérbios em sala de aula de matemática de vários níveis de ensino.
\end{abstract}

Palavras-chave: Categorização (Etno)matemática de Provérbios; Educação Básica; Etnomatemática; Matemática Elementar; Provérbios Populares Portugueses.

\begin{abstract}
Portuguese popular proverbs are of great wealth and contain knowledge and know-how in multiple areas of popular experience that must be discovered and preserved. We have no knowledge of studies on the ethnomathematics existing in Portuguese popular proverbs. Given the richness of these and the potential for use in the teaching and learning of mathematics, we propose to present here an initiating approach to the subject. From a core of about 2000 proverbs, at a first level of analysis we proceed to the identification of existing mathematical concepts. In a second level of analysis we categorise the mode (ethno)mathematics appears in Portuguese popular proverbs. We established three categories: Explicit Mode, Implicit Mode and Subtle Mode. We illustrate each category and explain the ethnomathematics involved in order to make clear the possible use of proverbs in the classroom of mathematics at various levels of education.
\end{abstract}

Keywords: Proverbs (Ethno)mathematics Categorization; Basic Education; Ethnomathematics; Elementary Mathematics; Portuguese Popular Proverbs.

\section{INTRODUÇÃO}

A cultura de um povo pode reconhecer-se de múltiplos modos. As tradições populares, muitas das vezes transmitidas através da oralidade, são um desses modos. Os provérbios são veículos de saberes populares (empíricos) transmitidos de geração em geração.

\footnotetext{
${ }^{1}$ UTAD - Universidade de Trás-os-Montes e Alto Douro, Vila Real, Portugal e CIDTFF - Centro de Investigação em Didática e Tecnologia na Formação de Formadores, Aveiro, Portugal. Email: mcosta@utad.pt
} 
Traduzem a referenciação histórico-psicológica de experiências vividas e do conhecimento da vida e do mundo que desse modo adquiriram.

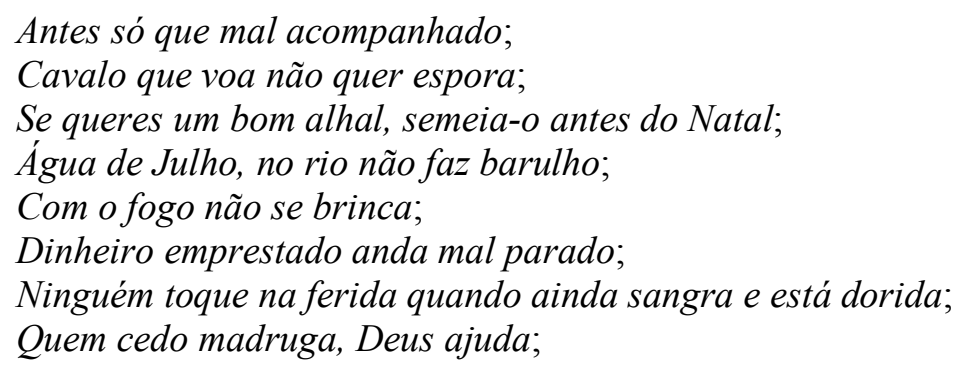

são exemplos da miríade de temas tratados nos provérbios e que vão desde os conselhos de relacionamento pessoal ou social à forma de lidar com animais e com as culturas agrícolas, passando por constatações sobre ensino, ciências naturais, físicas, económicas, médicas e religiosas.

Um estudo profundo sobre provérbios é o de (Lopes, 1992) cujo objetivo à data era “compreender e explicar o facto de os provérbios, fragmentos de uma sabedoria tradicional estereotipada, continuarem ainda hoje a ser invocados nas mais diversas situações, com um potencial surpreendente de flexibilidade de adequação contextual" (p. 1) e que ainda faz sentido, visto, em Portugal, se continuarem a invocar muitos provérbios. Os provérbios surgem em contexto cultural específico sendo, por vezes, extrapolados por analogia e aproximação para contextos mais alargados com variantes para o original, no entanto mantendo um núcleo de entendimento comum.

Em Portugal, existem estudos científicos sobre algumas das abordagens proverbiais, por exemplo: o de Mimoso (2008) focado na educação; o de Antão (2009) na saúde; o de Amaral (2014) na agricultura; e o de Rocha et al. (2016) no ensino das ciências físicas e naturais.

E na matemática? A matemática está, como em muitos outros casos, "escondida” (Gerdes, 1985) em diversos destes provérbios populares, tal como acontece, e está já bem documentado e revelado por estudos etnomatemáticos, em atividades e artefactos de povos indígenas ou grupos específicos. Relativos a diferentes zonas do mundo encontramos estudos etnomatemáticos na cestaria (Gerdes 2007a, 2007b; Kuoni, 2003), nos jogos tradicionais (Gerdes, 2008) e em armadilhas (Dias, Costa, \& Palhares, 2015), entre outros, nos quais os autores trazem à luz os saberes e saberes-fazer dos artesãos na criação desses artefactos. Também em Portugal se têm desenvolvido estudos deste tipo como o de Vieira, Palhares e Sarmento (2008), relativo à cestaria, o de Salta e Catarino 
Costa, C. (2020). Classificação dos modos como a (etno)matemática se expressa nos provérbios populares portugueses. Revista Latinoamericana de Etnomatemática, 13(2), 87- 108. DOI:

10.22267/relatem.20132.62

(2014) na agricultura, bem como os de Costa, Catarino e Nascimento (2008a; 2008b) sobre as atividades subsidiárias da agricultura, tanoaria e latoaria, na região do Douro em Portugal, muito conhecida pela produção do famoso vinho do Porto.

Não temos conhecimento de estudos sobre a etnomatemática existente nos provérbios populares, nem portugueses, nem de outros países. A Associação Internacional de Paremiologia, sedeada em Portugal, congrega investigadores de diversos países que se dedicam ao estudo científico dos provérbios. Em 2020, esta associação realizou o seu $14^{\circ}$ Colóquio Interdisciplinar sobre Provérbios (colóquio internacional). Até este colóquio, no qual apresentamos uma comunicação sobre a etnomatemática nos provérbios populares, tal nunca tinha ocorrido. Dada a riqueza destes pela cultura popular que guardam e a potencialidade de utilização no ensino e aprendizagem da matemática, propomo-nos apresentar aqui uma abordagem iniciadora ao assunto.

\section{METODOLOGIA}

Para proceder ao estudo etnomatemático a que nos propusemos era essencial ter um núcleo de provérbios com dimensão significativa. Recorremos a bases de dados de provérbios populares portugueses disponíveis na internet e aos livros (J. R. Costa, 2004) e (Parente, 2005). Esta listagem foi acrescentada com outros provérbios populares do nosso conhecimento ou daquele advindo por familiares e amigos de diferentes regiões do país.

A leitura e comparação destas fontes permitiu-nos construir uma lista de cerca de 2000 provérbios populares portugueses, sem repetições, mas manifestamente incompleta. Ainda assim, entendemos que esta servia o objetivo a que nos propusemos. Procedemos à análise etiológica desses provérbios no sentido de identificar aspetos matemáticos subjacentes e, se possível, estabelecer as principais características (etno)matemáticas definidoras de provérbios populares portugueses. É o resultado desta análise que apresentamos nas próximas secções.

A primeira etapa de análise consistiu na leitura desses provérbios e seleção daqueles que, de algum modo, a nossa "sensibilidade matemática" referenciou como contendo noções matemáticas (lato sensu). Usamos a expressão "sensibilidade matemática” para nos referirmos à formação em matemática e em didática da matemática que possuímos e que aprimora a nossa intuição e vivência cultural que também aqui foram essenciais. Deste modo, identificamos a referência a diversas noções matemáticas. 
A fase seguinte consistiu numa análise mais aprofundada dos provérbios selecionados, procurando estabelecer categorias relativas ao modo como a (etno)matemática surge nos provérbios populares portugueses. Estabelecemos três categorias - Modo 1 Explícito, Modo 2 Implícito e Modo 3 Subtil - que descrevemos na Tabela 1. Os Modos vão da interpretação mais acessível à mais complexa; note-se que o modo 3 é o mais indireto e subjetivo, o que é implícito tem, normalmente, uso pragmático, a subtileza vai para lá do implícito.

Tabela 1. Modos como a (etno)matemática surge nos provérbios populares portugueses

\begin{tabular}{|l|l|}
\hline \multicolumn{1}{|c|}{ Modos } & \multicolumn{1}{c|}{ Descrição } \\
\hline Modo 1 - Explícito & $\begin{array}{l}\text { Referências que exprimem diretamente aspetos matemáticos. As noções } \\
\text { matemáticas são usadas no provérbio com o seu significado próprio. }\end{array}$ \\
\hline Modo 2 - Implícito & $\begin{array}{l}\text { Referências que permitem inferir aspetos matemáticos. As noções } \\
\text { matemáticas são usadas no provérbio não diretamente, mas de modo a } \\
\text { serem acedidas com alguma dificuldade. }\end{array}$ \\
\hline Modo 3 - Subtil & $\begin{array}{l}\text { Referências que permitem subentender aspetos matemáticos. As noções } \\
\text { matemáticas são percebidas no provérbio dependendo de uma dimensão } \\
\text { própria de interpretação. }\end{array}$ \\
\hline
\end{tabular}

Fonte. Autora

\section{3. (ETNO)MATEMÁTICA IDENTIFICADA EM PROVÉRBIOS POPULARES PORTUGUESES}

A análise aos cerca de 2000 provérbios populares permitiu-nos identificar a referência a várias noções matemáticas, a saber: proto conceitos matemáticos (noções dimensionais, topológicas, etc.), função, número, relação de ordem, operações aritméticas, várias noções geométricas, medida e diferentes unidades de medida, tempo e dinheiro.

$\mathrm{Na}$ Tabela 2, listamos as noções identificadas as quais ilustramos com um ou dois dos provérbios onde se podem encontrar. Fica o desafio de encontrarem outros exemplos.

Tabela 2. Evidências de aspetos matemáticos explícitos em provérbios portugueses (Modo 1) Noção matemática Provérbio popular português (evidências)

\begin{tabular}{ll}
\hline \multicolumn{1}{c}{ Proto conceitos matemáticos } & \\
\hline Muitos, poucos, um & $\begin{array}{l}\text { Em terra de cegos quem tem um olho é rei } \\
\text { Quem muito fala, pouco acerta } \\
\text { Muitos poucos fazem muito }\end{array}$ \\
\hline Mais e menos & São mais as vozes que as nozes \\
\hline Noções espaciais & $\begin{array}{l}\text { Não ponhas o carro à frente dos bois } \\
\text { Mais vale lavrar o nosso ao longe do que o alheio ao perto }\end{array}$ \\
\hline Noite e dia & Faz da noite, noite; e do dia, dia e viverás com alegria \\
\hline Hoje, ontem e amanhã & Ontem vaqueiro, hoje cavaleiro \\
& Mais vale um hoje que dois amanhã \\
\hline \multicolumn{1}{c}{ Função } & \\
\hline Correspondência um para um & Cada macaco no seu galho \\
\hline
\end{tabular}


Costa, C. (2020). Classificação dos modos como a (etno)matemática se expressa nos provérbios populares portugueses. Revista Latinoamericana de Etnomatemática, 13(2), 87- 108. DOI:

10.22267/relatem.20132.62

\begin{tabular}{|c|c|}
\hline Proporcionalidade direta & Quanto maior a nau, maior a tormenta \\
\hline Proporcionalidade inversa & Tempo de Santa Luzia, cresce a noite, minga o dia \\
\hline \multicolumn{2}{|l|}{ Número } \\
\hline Número cardinal & $\begin{array}{l}\text { Quatro horas dorme o santo, cinco o que não é tanto, seis o } \\
\text { caminhante, oito o preguiçoso, nove o porco e mais só o morto. }\end{array}$ \\
\hline Número ordinal & Não há amor como o primeiro \\
\hline Numeral misto & Abóbora semeada na lua cheia dá abóbora e meia. \\
\hline Paridade & Cada um é um e cada dois é um par \\
\hline Noção de metade & Para bom entendedor meia palavra basta \\
\hline \multicolumn{2}{|l|}{ Relação de ordem } \\
\hline Noção de igualdade & Por S. Matias (22/2), noites iguais aos dias \\
\hline Noção de diferente & Passarinhos e pardais não são todos iguais \\
\hline Noção de maior que & A anca da vizinha é maior que a minha \\
\hline \multicolumn{2}{|c|}{ Operações aritméticas } \\
\hline Noção de adição & Três burros e um ignorante são quatro animais \\
\hline $\begin{array}{l}\text { Noção de dobro ou de } \\
\text { multiplicação por dois }\end{array}$ & $\begin{array}{l}\text { Em ano geado não há pão dobrado } \\
\text { Candeia que vai à frente alumia duas vezes }\end{array}$ \\
\hline \multicolumn{2}{|l|}{ Noções geométricas } \\
\hline Linhas & Deus escreve direito por linhas tortas. \\
\hline Noção de círculo & $\begin{array}{l}\text { Se a lua tem o círculo longe, água perto, se tem o círculo perto, } \\
\text { água longe }\end{array}$ \\
\hline Noção de circunferência & Lua à tardinha com seu anel dá chuva à noite a granel \\
\hline Formas geométricas & Bola de quatro cantos não chega aos paus \\
\hline \multicolumn{2}{|l|}{ Medida } \\
\hline Noção de medida & Tudo na vida quer peso e medida \\
\hline Unidade de medida & $\begin{array}{l}\text { O bem vende-se por onças e o mal por arrobas } \\
\text { Os homens não se medem aos palmos }\end{array}$ \\
\hline \multicolumn{2}{|l|}{ Tempo } \\
\hline Hora & Janeiro fora, uma hora e se bem contarás, mais meia hora acharás \\
\hline Dia, semana, mês, ano & $\begin{array}{l}\text { Largos dias têm cem anos } \\
\text { Pão de quinze dias, fome de três semanas } \\
\text { Cabrito de um mês, queijo de três }\end{array}$ \\
\hline \multicolumn{2}{|l|}{ Dinheiro } \\
\hline Unidades monetárias & Pelo Santiago (25/7) cada pinga vale um cruzado \\
\hline
\end{tabular}

\section{Fonte. Autora}

\section{4. (ETNO)MATEMÁTICA EXPRESSA DE MODO EXPLÍCITO NOS PROVÉRBIOS POPULARES PORTUGUESES}

Os provérbios apresentados na Tabela 2 são evidências do uso explícito das (respetivas) noções matemáticas nos mesmos.

Proto conceitos matemáticos são noções elementares basilares para a construção de posteriores noções matemáticas. Referimo-nos a noção de quantidade (muitos, poucos e 
um), a noções espácio-temporais (como: à frente, atrás, à direita, à esquerda, acima, zbaixo, longe e perto), a noções topológicas (como: dentro, fora e fronteira) e noções intuitivas de tempo (noite e dia; hoje, ontem e amanhã). Encontramos em alguns provérbios casos onde tais noções estão envolvidas que constam na Tabela 2 e acrescentamos aqui mais alguns exemplos:

Muita parra, pouca uva;

Devagar se vai ao longe;

Por fora bela viola, por dentro pão bolorento;

Azeite de cima, mel do meio e vinho do fundo, não enganam o mundo;

Não deixes para amanhã o que podes fazer hoje;

Quem vier atrás, feche a porta;

Longe da vista, longe do coração.

Em vários dos provérbios portugueses analisados é notória a existência de correspondências. Em alguns casos trata-se de correspondências unívocas, que como é sabido e relevante, estão na base da definição do conceito matemático de função. A cada elemento de um conjunto corresponde um e apenas um elemento de outro conjunto (eventualmente, do mesmo conjunto), como acontece, por exemplo em:

Cada cabeça sua sentença;

A cada bacorinho vem seu S. Martinho;

Cada terra com seu uso, cada roca com seu fuso;

Há sempre um testo para uma panela;

Em Janeiro cada ovelha com seu cordeiro.

Também encontramos contraexemplos para a noção de função, ou de forma mais elementar para a correspondência unívoca, ou seja, casos em que se trata de uma correspondência, mas não de uma correspondência unívoca, por exemplo em:

Cada um por si e Deus por todos;

Mais vale um cavalo com uma sela que três selas sem cavalo.

Estes dois exemplos são curiosos pela ligação entre uma afirmação que traduz uma correspondência unívoca (cada um por si; um cavalo com sela) e outra que não o é (uma em que se tem um para todos; e outra em que se tem três para nenhum).

Reconhecemos a noção de proporcionalidade direta e proporcionalidade inversa em vários dos provérbios analisados. Referimo-nos à ideia intuitiva de dadas duas variáveis, 
Costa, C. (2020). Classificação dos modos como a (etno)matemática se expressa nos provérbios populares portugueses. Revista Latinoamericana de Etnomatemática, 13(2), 87- 108. DOI:

10.22267/relatem.20132.62

uma variar em relação à outra de modo que aumentam ou diminuem em conjunto (proporcionalidade direta) ou quando uma aumenta a outra diminui (proporcionalidade inversa). No caso da proporcionalidade inversa, as ocorrências são em menor número. A seguir e a título ilustrativo indicamos provérbios em que consideramos estar patente a noção de proporcionalidade direta:

Quanto mais me bates, mais gosto de ti;

Quanto mais alto se sobe, maior é o trambolhão;

Quem a muitos há-de manter, muito há-de ter;

Para grandes males, grandes remédios.

Quanto à proporcionalidade inversa indicamos os provérbios:

Quem mais alto sobe, ao mais baixo vem parar;

Muito riso pouco siso;

Quem muito fala pouco acerta.

Nos provérbios populares portugueses os aspetos matemáticos mais óbvios são as referências a números. Encontramos ocorrências de numerais cardinais (números naturais), de numerais ordinais, bem como as noções de paridade e de metade.

Relativamente aos números naturais que aparecem, da primeira dezena identificamos referências a todos os números. São exemplos:

Mais vale um pássaro na mão que dois a voar;

Quando mija um português, mijam logo dois ou três;

Semeia alho-porro por Santa Ágata (5/2) e por cada rebento terás quatro;

Temos cinco dedos na mão e nenhum é igual;

Mais vale um gosto na vida do que seis vinténs na algibeira;

Quem em Janeiro lavrar tem sete pães para o jantar;

Nevoeiro de mais de três dias dura oito;

Dos Santos (1/11) ao São Martinho (11/11) são nove dias de pão e vinho.

Curiosamente, encontramos um só provérbio que reúne vários destes números (ver Tabela 2). Na dezena seguinte, encontramos referências ao 10,11, 14 e 15, deixamos aqui os exemplos:

Uma galinha sustenta dez pintos, mas dez pintos não sustentam uma galinha;

Se não és de bronze, deita-te às onze;

Sete oficios, catorze desgraças. 
Em relação às dezenas seguintes, aparecem referências a alguns múltiplos de cinco, nomeadamente, 20, 25, 30, 40, 80 e 90 .

Nem oito nem oitenta

é um exemplo. Os próximos provérbios têm a particularidade de conter vários desses números:

Dos quinze aos vinte, caso com quem o meu pai quiser; dos vinte aos vinte e cinco é com quem eu quiser; depois dos vinte e cinco, venha quem vier, não fica sem mulher.

Quem aos vinte não é, aos trinta não tem, aos quarenta não é ninguém.

Em nosso entender, em várias das referências ao número trinta está associada a noção de mês, ou seja, o número médio (30) de dias de um mês. É o caso dos seguintes:

Lua nova trovejada, trinta dias é molhada e se venta noventa;

Chovam trinta Maios e não chova em Junho.

Aparecem ainda referências ao 28 , associadas à particularidade do número de dias do mês de fevereiro, por exemplo em:

Fevereiro coxo, em seus dias vinte e oito;

Fevereiro tem 28 dias, é o mês em que as mulheres falam menos.

A referência à centena, ao milhar ou ao milhão (deste só encontramos uma ocorrência) é usada para traduzir a ideia de um número "muito grande". O mil ocorre muitas vezes, em contextos variados, mas sempre com esse sentido. Atente-se nos exemplos seguintes:

Ladrão que rouba a ladrão tem cem anos de perdão;

Escuta cem vezes e fala uma só;

Perdido por cem, perdido por mil;

Abril, águas mil;

Ao rico mil amigos se deparam ao pobre seus irmãos o desamparam;

Há mil modos de morrer e um só de nascer;

Quem só uma ovelha tem, mil lobos a comem;

Tostão a tostão faz um milhão.

Só encontramos uma referência explícita ao zero e que contém a noção de que a posição ocupada pelo zero num número tem relevância para a quantidade numérica envolvida, trata-se do provérbio:

Zero à esquerda não vale nada, do outro lado vale um ducado. 
Costa, C. (2020). Classificação dos modos como a (etno)matemática se expressa nos provérbios populares portugueses. Revista Latinoamericana de Etnomatemática, 13(2), 87- 108. DOI:

10.22267/relatem.20132.62

No entanto, o provérbio

Quem tem uma mãe tem tudo, quem não tem mãe não tem nada,

faz alusão à noção de nada, que intuitivamente associamos ao zero.

A utilização de numerais ordinais nos provérbios populares portugueses não é muito frequente, mas ainda assim encontramos referências a: primeiro, segundo, terceiro, quinto e sexto. Seguem-se algumas das ocorrências:

Não há amor como o primeiro;

Boa amizade segundo parentesco;

Céu escamado ao terceiro dia molhado;

Ao quinto dia verás que mês terás;

A lua como quinta assim pinta, se ao sexto dia não despinta, assim vai até aos trinta.

A noção de paridade está bem patente no provérbio seguinte que quase poderíamos considerar como uma "definição matemática":

Cada um é um e cada dois é um par.

A noção de metade é talvez o número racional mais elementar ou intuitivo, ao qual associamos o número decimal 0,5 ou a fração $1 / 2$. Esta noção encontra-se em várias ocorrências na lista de provérbios populares portugueses que analisamos. São exemplos:

Água e vento são meio sustento;

Rego aberto meia jeira é;

Meia vida é a candeia e o vinho outra meia;

De realçar neste último provérbio a ideia de as duas metades darem a unidade, ou seja, o conceito de metade. Encontramos um provérbio onde aparece a noção de um quarto, a saber:

O pisco em Janeiro vale os quartos de um carneiro.

Alguns dos exemplos encontrados apontam ainda para a noção de numeral misto, em particular $1 \frac{1}{2}$, isto é uma unidade e mais meia (ver Tabela 2, hora e meia, abóbora e meia).

A noção de igualdade reconhece-se em provérbios populares portugueses de dois modos diferentes. Ou usando expressamente a designação igual (ou não igual) ou recorrendo à comparação (tanto ... como...) a qual está associada à noção de igualdade. Seguem-se exemplos destas duas situações: 
A encomenda é igual ao cabaz;

De Santa Catarina (25/11) ao Natal, um mês igual;

Em Março tanto durmo como faço.

Tão ladrão é o que fica à porta como o que vai à horta;

S. João e S. Miguel passado, tanto manda o amo como o criado.

Identificamos o uso da operação de adição em alguns provérbios. Por exemplo, em:

Muitos poucos fazem muito

podemos reconhecer a noção elementar de que juntar várias quantidades de algo permite obter uma quantidade maior, o que leva à noção intuitiva de adição (de números naturais, claro). No provérbio

Se este coelho mato, com mais três faço quatro

está subjacente a adição $(1+3=4)$. Bem como em:

Tão certo como dois e dois serem quatro.

Tal como no caso da igualdade, há provérbios populares onde a noção de dobro é explícita, usando a designação dobrado, como acontece em:

Amores arrufados, amores dobrados;

Amigo disfarçado, inimigo dobrado;

Filhos criados trabalhos dobrados;

Morte desejada é vida dobrada;

e outros casos onde aparecem expressões do tipo vale por dois ou duas vezes para traduzir a mesma ideia. São exemplos destes casos os provérbios:

Homem prevenido vale por dois;

Quem compra barato, compra duas vezes;

Quem casa em Agosto, casa duas vezes;

Dá duas vezes quem prontamente dá.

O recurso a aspetos geométricos também está presente nos provérbios populares portugueses. Encontramos referências a linhas e a formas geométricas. Também a medida é um elemento frequente nestes provérbios.

A existência de referências geométricas intuitivas à noção de círculo e de circunferência é notória em vários provérbios, principalmente, nos que envolvem a lua e o sol. Nos mais antigos são usados os termos circo ou cerco para círculo ou circunferência (ainda que matematicamente sejam noções diferentes). São exemplos: 
Costa, C. (2020). Classificação dos modos como a (etno)matemática se expressa nos provérbios populares portugueses. Revista Latinoamericana de Etnomatemática, 13(2), 87- 108. DOI:

10.22267/relatem.20132.62

Lua com circo, água trás no bico;

Circo na lua, água na rua;

Cerco do sol molha o pastor.

As formas geométricas encontram-se em alguns provérbios, por exemplo, em:

Bola de quatro cantos não chega aos paus;

Este mundo é uma bola, quem anda nele é que se amola.

O primeiro deixa claro que a bola se distingue de outras formas geométricas (prismas) não podendo ter vértices, para se poder jogar. Quanto a "este mundo é uma bola" trata-se de uma metáfora muito usada e que remete para a forma aproximada da terra a uma esfera. O provérbio

Ter dois pesos e duas medidas

traduz, claramente, a ideia de que a cultura popular conhece e acede a noção de unidade de medida e da sua utilidade. A medida, a unidade de medida e, ainda, diversas grandezas são noções que ocorrem com frequência e em diferentes contextos nos provérbios populares portugueses, destacamos nos provérbios seguintes as grandezas que lhes estão associadas:

Feno alto ou baixo, em Junho é cegado (altura/comprimento);

Quando há dez léguas a andar, nove fazem metade do caminho (comprimento);

Mulher e sardinha querem-se da pequenina (altura);

Ouriços do S. João são do tamanho dum botão (volume);

De pequenino se torce o pepino (idade).

As medidas antropométricas estão, maioritariamente, representadas pelo palmo, embora também se encontrem outras. São exemplos os provérbios:

Do Natal à Sta. Luzia, cresce um palmo em cada dia;

A doença vem às braçadas e vai às polegadas.

Também a referência a medidas antigas é frequente, encontramos referências a alqueire, onça, arroba (ver Tabela 2):

Saber quantos pães tem um alqueire.

As noções de tempo e de dinheiro são consideradas da área da matemática escolar, nos primeiros anos de escolaridade e também nos provérbios se encontram muitas referências a estes temas. Começamos por apresentar um provérbio que os junta:

Tempo é dinheiro. 
Em relação ao tempo, considerando desde a unidade de tempo (segundo) até às estruturas dia, semana, mês, ano, apresentamos alguns exemplos:

Mais vale perder um minuto na vida do que a vida num minuto;

Não há Sábado sem sol, nem Domingo sem Missa, nem Segunda sem preguiça;

Remenda o teu pano, ele te durará um ano; se o tornares a remendar outro ano há-de durar.

E a terminar, a velha máxima:

Antes tarde do que nunca;

Quanto a provérbios que abordem o dinheiro, para além dos que referem explicitamente moeda, existem os que remetem para dinheiro em sentido lato:

Tostão a tostão, faz um milhão;

Cruzeiro a cruzeiro, faz um milheiro;

Goraz de Janeiro vale dinheiro;

Sapato branco em Janeiro é sinal de pouco dinheiro.

\section{5. (ETNO)MATEMÁTICA EXPRESSA DE MODO IMPLÍCITO NOS PROVÉRBIOS POPULARES PORTUGUESES}

A análise efetuada aos provérbios populares portugueses permitiu-nos inferir a referência a algumas das noções matemáticas já referidas na Tabela 2 e a outras, a saber: conjunto, número e sua construção, noções de máximo e mínimo, a propriedade transitiva das relações de ordem e algumas outras noções geométricas.

Na Tabela 3, listamos as noções identificadas as quais ilustramos com um dos provérbios onde se podem encontrar. Deixamos o desafio de descobrirem outros exemplos.

Tabela 3. Evidências de aspetos matemáticos implícitos em provérbios portugueses (Modo 2)

Noção matemática

\section{Conjunto}

Noção de conjunto

Noção de pertença
Provérbio popular português (evidências)

Fidalgos, galgos e pardais são três espécies de animais Filho de burro não pode ser cavalo

\begin{tabular}{|c|c|}
\hline Número & \\
\hline Número e sua construção & Grão a grão enche a galinha o papo \\
\hline \multicolumn{2}{|l|}{ Relação de ordem } \\
\hline Noção de máximo & Junta-te aos bons e serás melhor que eles \\
\hline Noção de mínimo & Junta-te aos maus e serás pior do que eles \\
\hline Propriedade transitiva & Os amigos dos meus amigos, meus amigos são \\
\hline \multicolumn{2}{|l|}{ Operações aritméticas } \\
\hline Noção de subtração & Quem tem cem e deve cem, pouco tem \\
\hline
\end{tabular}


Costa, C. (2020). Classificação dos modos como a (etno)matemática se expressa nos provérbios populares portugueses. Revista Latinoamericana de Etnomatemática, 13(2), 87- 108. DOI:

$10.22267 /$ relatem. 20132.62

\begin{tabular}{ll}
\hline Noção de multiplicação & Levanta-te às seis, almoça às dez, deita-te às dez, viverás dez vezes dez \\
\hline Noção de divisão & Rio que se divide torna-se ribeiro \\
\hline \multicolumn{1}{c}{ Noções geométricas } & \\
\hline Noção de ponto médio & No meio é que está a virtude \\
\hline Paralelismo & A par de ria, não compres vinha, nem olival, nem casaria \\
\hline Formas geométricas & Pedra que rola, não cria musgo \\
\hline \multicolumn{1}{c}{ Medida } & \\
\hline Noção de volume & Ouriços do S. João são do tamanho dum botão \\
\hline
\end{tabular}

Fonte. Autora

Comecemos pela noção intuitiva de número natural e da construção da sucessão de números naturais, $1,2,3,4, \ldots$, isto é, partindo do um obtemos os números naturais seguintes por adição de um, $2=1+1 ; 3=2+1$, etc..

O provérbio

Um dia, não são dias

cuja mensagem aponta para a particularidade de o que acontece num dia não ser norma nos outros, sugere a ideia matemática de que o um é intrinsecamente diferente dos outros números naturais a par da noção intuitiva da singularidade da unidade não ser suficiente para definir a norma da multiplicidade. Ainda em relação ao conjunto dos números naturais é de destacar a noção de conjunto discreto intrínseca a este conjunto de números, ao contrário do que acontece por exemplo com os números racionais. Podemos inferir estas ideias em:

Grão a grão enche a galinha o papo;

Quem conta um conto acrescenta-lhe um ponto;

Tostão a tostão faz um milhão;

Hora a hora Deus melhora.

O caso do provérbio

Não há duas sem três

enquadra-se nesta situação ao dar ideia da sequência dos números naturais, no entanto em termos de sentido de número (focando-nos na quantidade), matematicamente a afirmação correta seria Não há três sem duas uma vez que a quantidade três contém a quantidade dois. Hipoteticamente a composição "ilógica" da frase advém da acrescida facilidade de pronúncia desta sequência léxico-fonética comparativamente à sequência não há três sem 
duas, reforçada pela sugestão psicológica de acerto inscrita na ordem natural da sequência duas, três...

Em contrapartida o provérbio

Mais vale um pássaro na mão do que dois a voar

deixa claro que o sentido de número está corretamente adquirido pois ainda que dois seja maior do que um, a vivência real aponta para a diferença significativa entre o ter e o poder, eventualmente, vir a ter e aconselha que vale mais um (certo) que dois (incertos). Este provérbio aponta para a presença do princípio da incerteza popularmente percecionado no real, a par da ordem de diferenciação qualitativa entre o que existe e o que dessa existência é humanamente detido como posse.

O provérbio

Junta-te aos bons e serás melhor que eles, junta-te aos maus e serás pior do que eles permite-nos inferir as noções, respetivamente, de máximo e de mínimo. No entanto, não encontramos mais ocorrências deste tipo entre os provérbios analisados.

Em

Os amigos dos meus amigos, meus amigos são

rec-

onhecemos a propriedade transitiva, neste caso aplicada à relação de amizade. Se a é amigo de b e b é amigo de c, então a é amigo de c. No provérbio

Filhos das minhas filhas meus netos são, filhos dos meus filhos, serão ou não podemos considerar uma aproximação à propriedade transitiva (entendendo netos como “filhos" em segundo grau).

Identificamos o uso das operações de subtração, multiplicação e divisão em alguns provérbios, embora estas operações apareçam de forma implícita e num sentido muito intuitivo. É o caso da subtração e da divisão nos provérbios seguintes:

Quem tem cem e deve cem, pouco tem;

Quem paga o que deve sabe o que lhe fica;

Rio que se divide torna-se ribeiro;

Reparte o mal pelas aldeias;

Quem parte e reparte e fica com a pior parte, ou é tolo ou não tem arte. 
Costa, C. (2020). Classificação dos modos como a (etno)matemática se expressa nos provérbios populares portugueses. Revista Latinoamericana de Etnomatemática, 13(2), 87- 108. DOI:

10.22267/relatem.20132.62

Note-se que neste último provérbio temos um exemplo da divisão não equitativa, o que pode servir de reforço à compreensão da divisão equitativa.

Em relação à multiplicação encontramos um provérbio onde se infere que quem cumprir as indicações no mesmo viverá cem anos (dez vezes dez):

Levanta-te às seis, almoça às dez, deita-te às dez, viverás dez vezes dez.

É ainda de destacar a existência de provérbios populares portugueses que podemos designar como problemas de aritmética elementar. São deveras interessantes os provérbios cuja formulação ou compreensão implica a resolução de um problema. Atentese em alguns desses casos:

Porca com 3 meses, 3 semanas, 3 dias e 3 horas bacorinho fora (qual é o tempo de gestação de um bacorinho?);

Se chove no dia de Santa Ana (26/7), chove um mês e uma semana (quantos dias chove?);

Dos Santos (1/11) ao São Martinho (11/11) há doze manhãs de caminho (quantos dias decorrem entre estas festividades);

Se chove no dia se São Bento (21/3), choverá durante 37 dias mais três; Se chove no dia de S. Benedito, só 40 dias depois terás um dia bonito (duas versões do mesmo provérbio em que a parte da formulação matemática é equivalente, mas expressa num através da adição e no outro através do resultado);

A sebe dura três anos; o cão, três sebes; o cavalo, três cães; o homem, três cavalos; o corvo, três homens; e o elefante, três corvos (quantos anos dura cada um dos intervenientes?).

Terminamos estas reflexões sobre as operações aritméticas com um provérbio que dá conta do entendimento do senso comum do que é a natureza da aritmética:

Não é para amigo homem sem amizade, sendo certo que os erros da amizade são como aritmética aonde, para que a conta seja errada tanto vale errar em um como em um cento.

No que refere a noções geométricas podemos inferir a noção de ponto médio em provérbios como os seguintes:

No meio é que está a virtude;

Quando há dez léguas a andar, nove fazem metade do caminho. 
Note-se que o último provérbio pode ser usado para discutir a noção matemática do ponto médio do segmento a percorrer e a fadiga física após andar nove léguas, que parece faltar ainda outro tanto.

E a noção de paralelismo no provérbio:

A par de ria, não compres vinha, nem olival, nem casaria no sentido de perto e paralelo a cursos de água não ser conveniente ter bens. Em provérbios como:

Pedra que rola, não cria musgo depreende-se a referência a uma propriedade elementar dos sólidos de revolução - rolar - podendo a forma da pedra aproximar-se mais ou menos de uma esfera, um cilindro ou um cone.

Também a noção de volume pode ser inferida no provérbio

Ouriços do S. João são do tamanho dum botão

se associarmos o "tamanho" do ouriço (aproximadamente uma esfera) ao espaço que ocupa e, consequentemente, ao volume.

\section{6. (ETNO)MATEMÁTICA EXPRESSA DE MODO SUBTIL NOS PROVÉRBIOS POPULARES PORTUGUESES}

A análise efetuada aos provérbios populares portugueses permitiu-nos subentender noções matemáticas, a saber: noções de lógica elementar, noções ligadas ao estudo de funções, tipos especiais de sucessões, medida e infinito.

$\mathrm{Na}$ Tabela 4, listamos as noções que subentendemos, as quais ilustramos com um dos provérbios onde se podem encontrar. Fica o repto de explorarem outros provérbios na procura da matemática neles "escondida".

Tabela 4. Evidências de aspetos matemáticos subtis em provérbios portugueses (Modo 3) Noção matemática Provérbio popular português (evidências)

\section{Noções de lógica}

Operações lógicas elementares Inferência lógica

Preso por ter cão e preso por não ter

Deus dá nozes a quem não tem dentes e dá dentes a quem não tem nozes

\section{Função}

Estudo de funções (concavidades, máximos e mínimos)

\section{Sucessão}


Costa, C. (2020). Classificação dos modos como a (etno)matemática se expressa nos provérbios populares portugueses. Revista Latinoamericana de Etnomatemática, 13(2), 87- 108. DOI:

10.22267/relatem.20132.62

\begin{tabular}{ll}
\hline Progressão aritmética & Quem conta um conto, acrescenta um ponto \\
\hline Progressão geométrica & Dinheiro e santidade a metade da metade \\
\hline \multicolumn{1}{c}{ Medida } & \\
\hline Noção de volume & O saber não ocupa lugar \\
\hline \multicolumn{1}{c}{ Infinito } \\
\hline Noção de infinito & Basta um dito para um desgosto infinito \\
\hline
\end{tabular}

Fonte. Autora

Naturalmente que cada provérbio tem uma lógica interna ancorada no contexto cultural, mas em alguns também se subentende lógica matemática, ainda que possam conter incorreções ou incoerências. O provérbio

Preso por ter cão e preso por não ter

é curioso pela noção intrínseca que transmite indecidibilidade inescapável, a par da de impossibilidade ou falsidade, pois a conjugação de uma proposição com a sua negação é (sempre) falso, deixando quem o profere em situação de não ter o que fazer.

Também o provérbio

\section{Deus é bom e o Diabo não é mau}

apresenta aspetos de lógica matemática interessantes. Se considerarmos, que mau é a negação de bom, a proposição o Diabo não é mau contém uma dupla negação que, em lógica matemática é equivalente à afirmação, ou seja, não é verdade que o Diabo é mau, logo o Diabo é bom!

A implicação lógica também está patente em diversos provérbios populares portugueses. Atentemos no provérbio:

Se um não quer, dois não discutem,

E reescrevamo-lo em notação matemática:

Consideremos as proposições A: "O indivíduo A quer discutir" e B: "O indivíduo B quer discutir". Em notação matemática, o provérbio escreve-se: $\sim A \vee \sim B \Rightarrow \sim(A \wedge B)$, o que corresponde a uma das leis de De Morgan e, uma verdade matemática.

Já nos referimos a aspetos associados à noção de função no Modo 1, no entanto encontramos outros provérbios onde tal associação não é explícita, mas em nosso entender pode ser subentendida. O exemplo seguinte é paradigmático no caso do estudo de funções:

Não há dois altos sem um baixo no meio 
pois este inclui, entre outros: i) o estudo do gráfico da função; ii) o estudo de máximos e mínimos; e iii) o estudo da continuidade. Esperamos que a Figura 1, onde se representa o gráfico da função $\sin x \operatorname{com} x \in I R$, contribua para a interpretação matemática deste provérbio.

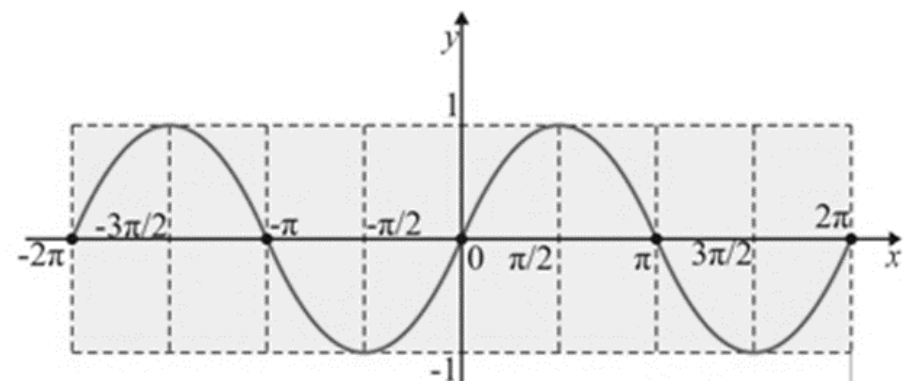

Figura 1. Gráfico da função $\sin x \operatorname{com} x \in I R$

Fonte. http://www.dex.ufla.br/Ivana/funcoestrigonometricas/index.html (05/12/2020,11:24) As sucessões são casos particulares de funções por estarem definidas no conjunto dos números naturais. Por sua vez as progressões são casos particulares de sucessões, obtendo-se a imagem de qualquer objeto pela adição algébrica de um mesmo número (razão) à imagem anterior (caso das progressões aritméticas) ou pela multiplicação de um mesmo número (caso das progressões geométricas).

Assim, em

\section{Quem conta um conto, acrescenta um ponto}

temos o princípio empírico de recursividade para obter a sucessão de números naturais de razão 1 .

E, em

\section{Dinheiro e santidade a metade da metade}

temos o princípio empírico de recursividade para obter a sucessão de números racionais de razão $1 / 2$.

O provérbio popular português

\section{O saber não ocupa espaço}

permite uma discussão interessante sobre materialidade e imaterialidade ligada, também, com a natureza dos objetos matemáticos, cuja abstração, nos permite dizer que "também não ocupam espaço", dado apenas utilizarmos representações desses objetos.

Finalmente, a noção de infinito. Noção (também) matemática complexa, que surge em alguns provérbios portugueses, nomeadamente, em

Basta um dito para um desgosto infinito 
Costa, C. (2020). Classificação dos modos como a (etno)matemática se expressa nos provérbios populares portugueses. Revista Latinoamericana de Etnomatemática, 13(2), 87- 108. DOI:

cuja particularidade de contrapor o um (o menor número natural) com o infinito o torna muito interessante.

A noção de infinito potencial pode ser subentendida em provérbios como

Tostão a tostão faz um milhão

Cruzeiro a cruzeiro faz um milheiro.

\section{QUE VANTAGENS SE ANTEVEEM DO USO DOS PROVÉRBIOS POPULARES PORTUGUESES NO ENSINO DA MATEMÁTICA?}

Estabelecido que existe (etno)matemática em muitos dos provérbios populares portugueses e em três modos distintos - explícito, implícito e subtil - há conteúdo matemático para abordar em sala de aula de matemática em vários níveis de ensino.

Entendemos que as noções matemáticas identificadas no Modo 1 - Explícito serão adequadas aos primeiros anos de escolaridade do $1 .^{\circ}$ ciclo do ensino básico, excetuando as relativas a proto conceitos matemáticos que se adequam à educação pré-escolar. As consideradas no Modo 2 - Implícito, serão adequadas aos $3 .^{\circ}$ e $4 .^{\circ}$ anos de escolaridade, tendo potencial para ser utilizadas no $2 .^{\circ}$ ciclo do ensino básico. As noções matemáticas incluídas no Modo 3 - Subtil adequam-se, preferencialmente, ao ensino secundário, onde a capacidade de abstração e conhecimentos matemáticos surgem mais desenvolvidos. É de referir que o mesmo provérbio pode ser usado em níveis de escolaridade diferentes, é exemplo o provérbio

\section{Quem muito fala, pouco acerta}

que tanto pode ser utilizado num nível muito elementar, para abordar proto conceitos matemáticos de muito e pouco, como mais tarde aquando do estudo da proporcionalidade inversa.

A utilização de provérbios populares portugueses, em sala de aula de matemática, permitirá criar tarefas com contexto cultural (real). Estas tarefas conduzirão os alunos a desenvolver atividades tais como: i) leitura e interpretação do provérbio; ii) identificação e contextualização das noções matemáticas nele envolvidas; iii) análise crítica das mesmas; e iv) construção de conhecimento matemático novo.

Estas atividades têm, claramente, um cariz interdisciplinar pela própria natureza dos provérbios, uma vez que estes abordam temas variados que podem ser tratados em disciplinas como ciências da natureza, estudo do meio, e, evidentemente, português. 
A partir de um determinado provérbio (um ou mais do que um) pedagogicamente escolhido, pode ser desenvolvido um projeto ou uma tarefa interdisciplinar. A interpretação do provérbio, dependendo do nível de escolaridade dos alunos por quem vai ser estudado, envolve não só a língua portuguesa, mas também: (i) a educação cívica, no sentido de refletir sobre aspetos éticos, xenófobos, racistas, ecológicos, entre outros, eventualmente, existentes no provérbio; (ii) a história, estudo do meio ou geografia, no sentido de contextualizar o provérbio no tempo e espaço onde surgiu; (iii) as ciências naturais, no sentido de avaliar da validade das ilações contidas no provérbio (iv) a filosofia, no sentido de entender os provérbios como construção cultural, de sistematização e por vezes simplificação de conhecimento, não intemporal, não universal, entre outros aspetos; e também a matemática, como mostramos neste estudo. Caberá ao professor a sabedoria de adequar estas reflexões à idade dos alunos, no sentido de contribuir para uma formação global e integrada dos mesmos. Este é, em nossa opinião, o maior contributo da etnomatemática como "matemática escondida" para o ensino e a aprendizagem da matemática.

Entendemos que o contacto por parte dos alunos com o saber e saber-fazer popular contido nos provérbios, contribui para formar e propiciar uma visão mais ampla do horizonte e dimensão cultural da sua terra e do seu país.

\section{NOTAS FINAIS}

O estudo etnomatemático dos provérbios populares portugueses aqui apresentado não pretende ser exaustivo, mas consideramos a categorização que propomos pode constituirse como ponto de partida para outros estudos. Procuramos propor explicações para muitos dos aspetos etnomatemáticos identificados o que serve de guião para a sua utilização em sala de aula de matemática a professores que pretendam experimentar nas suas práticas provérbios populares portugueses.

\section{AGRADECIMENTOS}

A autora agradece aos Professores Rui e Marinela Soares da Associação Internacional de Paremiologia o desafio que lhe fizeram em dedicar-se ao estudo da matemática nos provérbios populares portugueses; a Soledade Costa a dedicação, empenho e colaboração na recolha dos provérbios e a António Faceira as reflexões conjuntas e sugestões de 
Costa, C. (2020). Classificação dos modos como a (etno)matemática se expressa nos provérbios populares portugueses. Revista Latinoamericana de Etnomatemática, 13(2), 87- 108. DOI:

melhoramento da versão final do texto. Justifica-se ainda um agradecimento aos revisores deste artigo cujas sugestões e críticas possibilitaram melhorar a versão final do texto.

\section{REFERÊNCIAS}

Amaral, P. (2014). Análise da Fundamentação Agronómica dos Provérbios Agrícolas Portugueses (tese de mestrado não publicada). Lisboa, Portugal: ISA Universidade de Lisboa.

Antão, C. (2009). A importância dos provérbios na promoção da saúde (tese de doutoramento não publicada). Badajoz, Espanha: Universidade de Estremadura.

Costa, C., Catarino, P. \& Nascimento, M. (2008a). Tanoeiros em Trás-os-Montes e Alto Douro: saberes (etno)matemáticos. In P. Palhares (Ed.). Etnomatemática Um olhar sobre a Diversidade Cultural e a Aprendizagem Matemática. (pp. 193-233). V.N. Famalicão: Edições Húmus.

Costa, C., Catarino, P. \& Nascimento, M. (2008b). Latoeiros em Trás-os-Montes e Alto Douro: saberes (etno)matemáticos. In P. Palhares (Ed.). Etnomatemática Um olhar sobre a Diversidade Cultural e a Aprendizagem Matemática. (pp. 235-264). V.N. Famalicão: Edições Húmus.

Costa, J. (2004). O Livro dos Provérbios Portugueses (2 ${ }^{\mathrm{a}}$ Ed.). Lisboa: Editorial Presença.

Dias, D., Costa, C., \& Palhares, P. (2015). Os saberes matemáticos em armadilhas dos caçadores Nyaneka-nkhumbi do sul de Angola. Revista Latinoamericana de Etnomatemática, 8(2), 326-340.

Frases e Provérbios. http://www.fraseseproverbios.com/proverbios-portugueses.php $05 / 12 / 2020$ às $11: 29$

Gerdes, P. (1985). Conditions and strategies for emancipatory mathematics education in underdeveloped countries. For the Learning of Mathematics, 5(3), 15-20.

Gerdes, P. (2007a). Otthava. Fazer cestos e geometria na cultura Makhuva do Nordeste de Moçambique. Nampula: Universidade Lúrio.

Gerdes, P. (2007b). Geometria e cestaria dos Bora na Amazônia peruana. Morrisville, NC: Lulu.com.

Gerdes, P. (2008). Jogos e puzzles de meioquadrados. Maputo: Editora Girafa.

Kuoni, B. (2003). Cestería Tradicional Ibérica. Barcelona: Ediciones del Aguazul.

Lopes, A. (1992). Texto Proverbial Português. Elementos para uma análise semântica e pragmática (Tese de doutoramento não publicada). Universidade de Coimbra, Coimbra. Consultada

em https://estudogeral.sib.uc.pt/bitstream/10316/719/2/Texto\%20Proverbial\%20Port ugu $\% \mathrm{C} 3 \%$ AAs.pdf

Mimoso, A. (2008). Provérbios: uma fonte para a História da Educação. Revista Lusófona de Educação, 12, 155-163.

Parente, S. (2005). O Livro dos Provérbios. Barcelos: Círculo dos Leitores.

Rocha, J., Pinto, A., Gomes, J., \& Oliveira, E. (2016). Dos provérbios ao conhecimento científico: de poeta e cientista inventor todos temos um pouco com algum labor- 
o ensino das ciências físicas e naturais no $1 .^{\circ}$ e $2 .^{\circ}$ ciclos do ensino básico. Indagatio Didactica, 8(4), 53-61.

Salta, E., \& Catarino, P. (2014). Práticas Etnomatemáticas de agricultores do Douro: das vinhas ao olival. Acta Scientiae, 16(3), 422-444.

Soares, M. (2015). Provérbios de Aperitivo. Tavira: Associação Internacional de Paremiologia.

Soares, R. (2014). Cada monumento, seu momento / Cada momento, seu monumento. Agenda proverbial. Tavira: Associação Internacional de Paremiologia.

Vieira, L., Palhares, P. \& Sarmento, M. (2008). Etnomatemática: estudo de elementos geométricos presentes na cestaria. In P. Palhares (Coord.). Etnomatemática - Um Olhar sobre a Diversidade Cultural e a Aprendizagem Matemática (291-315). Ribeirão: Edições Húmus. Recuperado de http://www.emaildivertido.com/2010/03/todos-os-ditados-populares-portugueses.html 5/2/2017 às 11:03 